\title{
Keeping the Pace in CS-1 Through the Use of CMS
}

\author{
Dr. Can Kültür \\ Bilkent University \\ Department of Computer and Instructional \\ Technology Teacher Education, Ankara, Turkey \\ +90-312-290 3362 \\ kultur@bilkent.edu.tr
}

\begin{abstract}
In this poster, it is aimed to share the experience of using course management systems (CMS) in a CS-1 course. The aim was to focus on the individual needs of students while learning programming. Creating a social online environment for solving exercises and sharing solutions seemed to be effective to support instructors as well as students.
\end{abstract}

\section{Categories and Subject Descriptors}

K.3.1 [Computer Uses in Education]: Collaborative Learning

K.3.2 [Computer and Information science education]: Computer science education

\section{General Terms}

Documentation, Management.

\section{Keywords}

Introduction to programming, collaboration, course management system, course design, student motivation.

\section{INTRODUCTION}

Introduction to programming is a challenging course for both students and instructors. Lots of strategies and tactics had been proposed for the success of such courses. Among them, the ones targeting individual needs of students are challenging. On the other hand, it is easier to categorize the individual needs of students, which can be critical for the success of the whole course. In this manner, using a CMS (like Moodle) to meet the needs of the students seems to provide an effective solution.

\section{FOCUSING ON NEEDS}

Depending on observations and previous experiences in teaching CS-1 courses, the instructor believed that it is very important to support the students when they need. In this manner, some critical issues can be listed as:

- Students should write programs as much as they can. So, they need various exercises or problems.

- $\quad$ Students should be able to read and find mistakes of others' programs. So, it is important to generate many erroneous programs.
- Students should be able to provide and understand alternative solutions to the same problems. So, they need to see others' solutions.

- $\quad$ Students tend to give up studying, when they cannot find solutions by themselves. When they just postpone, in the following days, most of them do not ask for help. So, it is important to support students while they are studying.

- The resources of the instructors are limited. So, in order to meet these needs, some mechanisms supporting collaboration are needed.

\section{USING CMS AS A SOLUTION}

Considering such issues, the instructor thought that giving lots of simple home exercises in an online environment might help. In this context, Moodle's special forum type, which was named as "Question and Answer (Q/A)", provided a mechanism. In this type of forum, students must first respond to the forum topic (home exercises) before seeing the answers of other students. The instructor prepared weekly home exercises in a regular format. In the lectures, he encouraged the students to solve those simple questions at home and help each other by giving clues. As a result, students provide erroneous programs, alternative solutions and online support to each other.

Another focus on the process is instructors' getting feedback from the students. Instructor can monitor the student performances before the next lecture and redesign the lecture accordingly.

\section{RESULTS AND CONCLUSION}

It was observed that student participation was very high, and the learning objectives were achieved. So, such an approach is worth to consider in CS-1 courses, since it supports students in (1) writing programs, (2) getting help from friends as soon as possible where an instructor will not be able to answer all those questions, (3) producing mistakes to be solved by others, (4) generating and reading alternative solutions. Additionally, the efforts of individual instructors may not be enough for producing such material in the tight schedules of CS-1 courses. Using Q/A type forum of CMS seem to support instructors as well as students. 